\title{
A importância da criatividade no trabalho artesanal dos grupos produtivos de um programa de Economia Solidária
}

\author{
The importance of creativity in work groups of craft production of \\ Solidarity Economy Program
}

\author{
Preto, Seila Cibele Sitta; Mestranda; \\ Universidade Federal de Santa Catarina - UFSC \\ cibelesittap@gmail.com \\ Fialho, Francisco Antônio Pereira ; Doutor; \\ Universidade Federal de Santa Catarina - UFSC \\ fapfialho@gmail.com \\ Figueiredo, Luiz Fernando Gonçalves de; Doutor; \\ Universidade Federal de Santa Catarina - UFSC \\ Iff@cce.ufsc.br
}

\begin{abstract}
RESUMO
No mercado de trabalho a competitividade é muito grande e excludente, deixando muitas pessoas sem emprego. O governo tem o papel de distribuir da renda por meio de programas governamentais. A economia solidária proporciona uma forma diferente de trabalho e renda dentro de condições de desemprego ou situação de vulnerabilidade social. Portanto, este artigo apresenta alguns grupos produtivos da economia solidaria com seus respectivos produtos solidários. Diante deste contexto, este trabalho pretende discorrer sobre o tema da criatividade e potencial criativo, sobre o contexto da economia solidária e a apresentação de grupos produtivos e seus trabalhos de produtos solidários. A pesquisa tem como questão norteadora: Como a criatividade pode potencializar o trabalho artesanal dos grupos produtivos solidários? Este artigo tem como objetivo mostrar como a criatividade pode valorizar e diferenciar o trabalho dos grupos produtivos de um programa de Economia Solidária.
\end{abstract}

Palavras-Chave: Criatividade; Economia solidária; Grupos produtivos.

\begin{abstract}
In a competitive labor market is very large and exclusionary, leaving many people without jobs. The government has the role of distributing income through government programs. The solidarity economy provides a different way of working and income conditions in unemployment or social vulnerability. Therefore, this article presents some of the solidarity economy productive groups with their respective products in solidarity. Given this context, this paper aims to discuss the theme of creativity and creative potential of the context of the solidarity economy groups and present their work productive and supportive products. The research has the question: How creativity can enhance the craftsmanship of solidarity production groups? This article aims to show how creativity can enhance and differentiate the work of productive groups of a program of the Solidarity Economy.
\end{abstract}

Keywords: Creativity, Solidarity Economy; Groups productive.

\section{Introdução}


No mercado de trabalho a competitividade é muito grande e excludente, deixando muitas pessoas sem emprego. $O$ desemprego em certas épocas do ano pode elevar ou diminuir. Neste sentido, os excluídos do mercado de trabalho e classes mais pobres têm desenvolvido outros mecanismos de enfrentamento ao desemprego. A Economia Solidária proporciona uma forma diferente de trabalho e renda dentro de condições de desemprego ou situação de vulnerabilidade social.

Segundo HARMAN, W; HORMANN, J., (1990, p.33) ele diz que:

“Em resposta as ostensivas desigualdades na distribuição da renda de acordo coma produtividade e diante da persistência do desemprego e da "impossibilidade de empregar" alguns trabalhadores, o papel do governo na redistribuição da renda tem crescido de forma considerável na maioria dos países. Essa redistribuição governamental e realizada através de transferências diretas e pagamentos, como seguro social e programas de assistência social;".

Diante deste contexto, este trabalho pretende discorrer sobre a importância da criatividade e do potencial criativo, nos grupos produtivos da Economia Solidária na geração de trabalho e renda, inclusão social, autogestão e sustentabilidade dos grupos.

Para tanto, a pesquisa tem como questão norteadora: Como a criatividade pode potencializar o trabalho artesanal dos grupos produtivos solidários?

Este artigo tem como objetivo mostrar como a criatividade pode valorizar e diferenciar o trabalho dos grupos produtivos de um programa de Economia Solidária.

\section{Criatividade e Potencial Criativo}

A criatividade humana só tem razão para a sua existência, se nela for encontrado um caráter produtivo, este de transformação social e/ou individual. E o valor da criatividade humana esta na possiblidade de mudar a vida das pessoas, criando novas atividades. E para criar é necessário fantasiar. A fantasia é um componente necessário, e ocorre através do sujeito e pelo meio social, mediado pelo trabalho.

De acordo com Ostrower, (1999, p.31),

“o homem elabora seu potencial criador através do trabalho. É uma experiência vital. Nela o homem encontra sua humanidade ao realizar tarefas essenciais a vida humana e essencialmente humanas. A criação se desdobra no trabalho porquanto este traz em si a necessidade que gera as possíveis soluções criativas. Nem na arte existiria criatividade se não pudéssemos encarar o fazer artístico como trabalho, como fazer intencional produtivo e necessário que amplia em nós a capacidade de viver. Retirando da arte o caráter de trabalho, ela é reduzida a algo de supérfluo, enfeite talvez, porém prescindível a existência humana".

A criatividade não é um simples imaginar, mas uma atividade que demanda trabalho, pois seguem etapas de criação e é necessário ter um trabalho organizado e sistemático. E para que isso aconteça é preciso obter o conhecimento da realidade e a capacidade de fantasiar.

O conhecimento da realidade demanda de uma atividade laborativa e criativa, devido às necessidades que nos rodeiam. Já a fantasia, é o imaginar por meio de combinações que não existem, pois, se existe um problema é porque não foi inventado ainda uma solução, então precisa ser imaginada, fantasiada uma solução.

Zanluchi (2005, p.32) diz que,

“criar é poder libertar-se da concretude do real, mas mantendo-se a ele vinculado. Esse vínculo é importante, já que a fantasia, apesar de livre, não é descompromissada. Ela tem um compromisso com o real e suas possibilidades, com o problema e suas necessidades." 
Para que seja eficaz a relação entre fantasia e realidade e necessário o amadurecimento da imaginação. Este amadurecimento se divide em três etapas segundo Zanluchi apud Rubinstein (1973). A primeira etapa é a fase da infância, onde o indivíduo necessita de objetos concretos para se expressar, tendo dificuldades de abstração. Na segunda etapa que é a fase da adolescência, o indivíduo já não necessita de objetos para fantasiar, porém é uma fase pouco produtiva, pois o adolescente imagina muita coisa e coloca pouquíssimo dessa imaginação em prática. E terceira e última etapa, é a fase da imaginação amadurecida, que, ao passar pelas etapas anteriores obtendo a imaginação mais amadurecida, tem-se a capacidade de modelagem de produtos por meio de objetos palpáveis ou verificáveis. Pois, a imaginação amadurecida permite a criação de novas coisas e a aplicação destas na prática. (Zanluchi, 2005, p.33).

Portanto percebe-se que a realidade alimenta a fantasia e a fantasia pode criar uma nova realidade. Quanto mais e melhor for à experiência de um indivíduo, melhor desempenho terá em sua capacidade imaginativa.

Durante o desenvolvimento do processo criativo é importante também levar em conta a emoção, pois ela esta diretamente ligada com a imaginação e o sentimento.

Vygotsky (2001, p.139) afirma que:

"Toda emoção é um chamamento á ação ou a uma renúncia a ela. Nenhum sentimento pode permanecer indiferente e infrutífero no comportamento. As emoções são esse organizador interno das nossas reações, que retesam, excitam, estimulam ou inibem essas ou aquelas reações. Desse modo, a emoção mantém seu papel de organizador interno do nosso comportamento".

Cada indivíduo então tem uma maneira de reagir às situações emocionais, isso devido a peculiaridades de cultura, condições sociais e de acordo com a sua própria história pessoal.

Portanto, pode-se afirmar que os seres humanos são dotados de criatividades por natureza.

Veremos logo abaixo no quadro 01, algumas definições e conceitos sobre criatividade.

Quadro 01 - Conceitos e definições de criatividade.

"potencial inerente ao homem, e a realização desse potencial uma de suas necessidades".
FAYGA

$(2007$, p.5)

“Criar é, basicamente, formar. É poder dar uma forma a algo novo. [...]. O ato criador abrange, portanto, a capacidade de compreender; e esta por sua vez, a de relacionar, ordenar, configurar e significar."

FAYGA

(2007, p.9)

"processo que resulta na emergência de um novo produto (bem ou serviço) aceito, como útil, satisfatório e/ou de valor por um numero significa-

ALENCAR, tivo de pessoas em algum ponto no tempo".

(1996, p.15).

"Faculdade ou atributo de quem ou do que é criativo; capacidade de

DICIONÁRIO

criar coisas novas".

AURÉLIO, 2012.

“[...] não é um jogo de livre imaginação e sim uma atividade que exige grande trabalho, e que em todas as etapas da criação é necessário um

ZANLUCHI (2005) trabalho organizado e sistemático".

(1969). 
"Competência mental de raciocinar de forma diferente do computador, isto é, articulando o que não é previsto na lógica com a própria logica. Se PREDEBOM (2002, não houver a articulação, não é criatividade, é só fantasia".

Fonte: própria, 2012.

Normalmente as perguntas que o homem faz ou as soluções que ele encontra, por meio do agir, do imaginar ou do sonhar, tem uma relação sempre direta com a forma.

Segundo FAYGA (2007, p. 10) “O homem cria, não apenas porque quer, ou porque gosta, e sim porque precisa; ele só pode crescer enquanto ser humano, coerentemente, ordenando e dando forma, criando".

O homem possui qualidades comportamentais inatas, sendo um ser consciente e sensível. E é por meio dessas qualidades que se desenvolve seu potencial criativo. $O$ aspecto cultural contribui para o conhecimento da realidade e de imaginar suas fantasias. Porém, independente do contexto cultural, o homem continua sendo um ser consciente e sensível. A cultura representa o desenvolvimento social do homem e sua forma de convívio com as pessoas. cutural"

Abaixo tem-se a representação visual pela figura 01 da tríade do "ser consciente-sensível-

Figura 01: Tríade do "ser consciente-sensível-cutural"

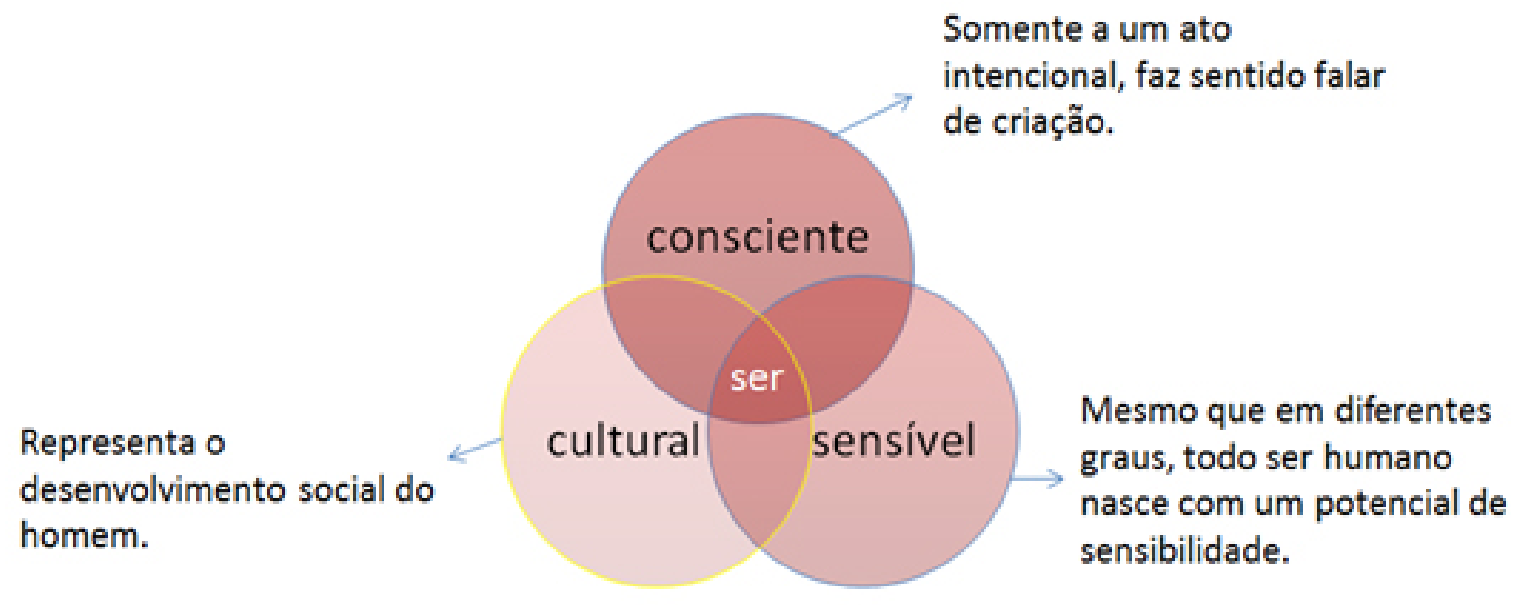

Fonte: Adaptado de Fayga (2007, p.11).

Portanto "o homem elabora seu potencial criador através do trabalho. [...] a criação se desdobra no trabalho porquanto este traz em si a necessidade que gera as possíveis soluções criativas." (FAYGA, 2007:31)

De Masi (2005, p.156), ao tratar da produção de criatividade em organizações, observa que não é "obrigar as pessoas concretas a serem mais imaginativas, ou as pessoas imaginativas a serem mais concretas", mas é, sim, "formar misturas equilibradas de pessoas imaginativas e de pessoas concretas, cada uma delas coerente consigo mesma e fiel à própria vocação natural".

Ainda De Masi (2005, p.153), diz que o ato criativo necessita de instrumentos e de técnicas com as quais se podem transformar fantasias em obras concretas.

Existem modelos propostos por autores, para o desenvolvimento da criatividade. Alencar, $(1997$, p.27) propõe o modelo, conforme figura abaixo: 
Figura 02: Modelo para desenvolvimento da criatividade proposto por Alencar em 1993.

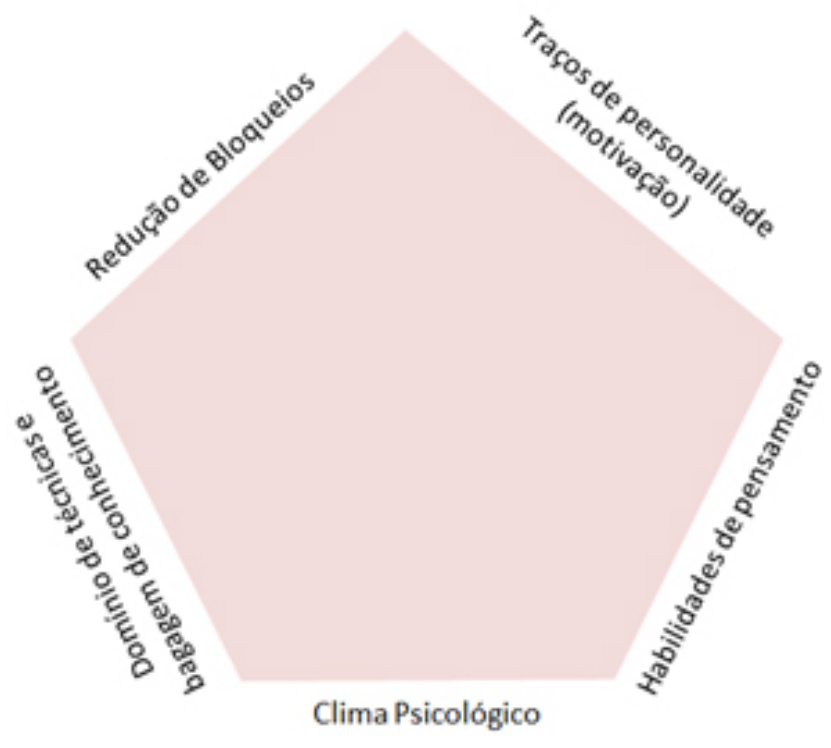

Fonte: A gerencia da Criatividade (1997, p.27).

A criatividade ocorre, de acordo com o contexto social, e depende de processos de pensamentos que têm suas raízes mais profundas na cultura. Tanto as normas como tradições, os valores, os tabus, os sistemas de incentivo e punições afetam sua expressão. O papel crucial do ambiente social é inquestionável e tem sido apontado pelos mais diversos autores, como Stein (1974), que assim expressou:

\begin{abstract}
"estimular a criatividade envolve não apenas estimular o indivíduo, mas também afetar o seu ambiente social e as pessoas que nele vivem. Se aqueles que circundam o indivíduo não valorizam a criatividade, não oferecem ambiente de apoio necessário, não aceitam o trabalho criativo quando este é apresentado, então é possível que os esforços criativos do indivíduo encontrem obstáculos sérios, senão instransponíveis." (p.XII)
\end{abstract}

"Para desenvolver novas ideias, é necessário também visualizar a realidade de muitos pontos de vida, examinar os problemas de mais de uma perspectiva, deixando de lado nossos próprios pontos de vista e concepções." (ALENCAR, 1996:33)

O clima também é fator que favorece o comportamento criativo. Alencar diz que:

A criatividade vem se acentuando cada dia mais nas organizações pelas mudanças do mundo, que a cada dia se inova deixando para segundo plano o conservadorismo.

A prática de exercícios ou técnicas de criatividade é importante para combater os bloqueios e utilizar a imaginação, o sistema não lógico e o desconhecido. (PREDEBOM, 2002, p.170).

Com essas práticas as pessoas são induzidas a se exporem mais, o que acaba facilitando a integração do grupo. Usa-se mais a imaginação, o que é inato ao homem, porém com o passar do tempo essa qualidade vai se perdendo.

Predebom (2002, p.174) afirma que, "nascemos sabendo voar com a imaginação. Quando adultos perdemos essa liberdade, inibidos pelo compromisso com a realidade". Predebom ainda sugere algumas dicas para o trabalho em grupos criativos:

- Os integrantes devem considerar o grupo como uma equipe, onde ganham todos ou perdem todos juntos.

- "Respeito mútuo, o grande princípio. Encorajamento recíproco, a grande chave. Motivação, 
a grande porta. Inovação, a grande meta".

- Todas as pessoas são diferentes, assim podem se completar, cultivando a harmonia nas diferenças.

- "Da quantidade vem à qualidade: abrir um leque de alternativas e explorar. Por que ficar com uma só ideia? Porque não admitir outra nova? Porque não tentar melhorá-la?". (PREDEBOM, 2002, p.209).

Com o trabalho de grupo consegue-se descobrir oportunidades devido às trocas de informações. Essas trocas de informações e aquisição de conhecimento, estão no cotidiano das pessoas, e no trabalho dos grupos produtivos.

O fator colaboração ou parceria criativa é fundamental para a exploração do potencial criativo das outras pessoas.

Estar motivado também é fator crucial para o desenvolvimento da criatividade. "fazer parte de uma equipe motivada pelo ideal de uma meta é outro caso: vê-se despertar no grupo uma energia contagiante e passamos a vivê-la intensamente, mobilizando toda a competência". (PREDEBOM, 2002, p.145).

O grande segredo é o interesse pelo trabalho, este não deve ser pensado somente como ganhar dinheiro, e sim como um caminho para o crescimento pessoal, para contribuição a sociedade, como ser humano ativo e produtivo.

Segundo Predebom, (2002, p.156) diz que "quanto menos definitivo/imutável for nosso planejamento de produção, mais facilmente poderemos adaptar o produto as contingencias do mercado".

Estar aberto às mudanças ou aperfeiçoamentos não abre espaço só a criatividade, mas a sobrevivência da equipe ou do grupo produtivo.

De acordo com Ayam (1998, p.69) em seu livro, diz que:

"uma das maneiras mais poderosas de explorar o potencial criativo de outras pessoas é criar uma parceria, ou aliança formal, com um ou mais indivíduos, para trabalhar em um empreendimento criativo específico".

Ayam ainda relata cinco parâmetros que visam o sucesso da colaboração:

1. Definir a visão da aliança ou colaboração. Qual é o escopo de sua aliança. Quanto tempo irá durar. Desenvolva uma definição que cada participante deverá aceitar.

2. Certifique-se de cada pessoas oferece não só recursos e ideias, mas também colhe benefícios. Quando uma pessoa em uma relação é forçada a carregar as responsabilidades econômicas ou emocionais, logo se sente chateada e insatisfeita. Estruture a sua parceria para que cada pessoa tenha oportunidade de beneficiar-se e contribuir.

3. Não abandone a estrutura. A criatividade geralmente não é subproduto natural de um ambiente altamente estruturado, mas uma certa estrutura ajudará a concentrar os esforços na mesma direção.

4. Lide com os problemas à medida que surgirem. A maneira mais rápida de destruir a colaboração é permitir que a negatividade, a falta de confiança ou a raiva se desenvolvam. [...] 5. Escreva. Um acordo de parceria é importante, mesmo que você tenha baixíssima expectativa de lucro, e que seu parceiro seja seu melhor amigo.

Portanto trocar ideias e compartilha-las na maioria das vezes geram resultados extremamente valiosos, sendo válido para todo o grupo ou empreendimento criativo.

Outra forma de colocar a criatividade em prática é por meio das comunidades criativas. Estas são formadas por pessoas que se reúnem para compartilhar interesses em comum. Elas podem ser formalizadas, por meio de escolas entre outros, ou serem informais, seguindo livremente suas reuniões para a discussão de qualquer assunto de interesse comum. Por meio das comunidades criativas, os integrantes adquirem novos conhecimentos e apoio construtivo para o seu trabalho. 


\title{
Comunidades Criativas, Comunidades de Prática e Grupos Produtivos Solidários
}

Há muitas relações entre esses três conceitos, comunidades criativas, comunidades de prática e grupos produtivos. No entanto, seus conceitos ainda são confusos devido as suas similaridades. Desta forma o artigo visa o esclarecimento dos conceitos.

De Masi (2003) declara sobre grupos criativos, o qual para ele é "um sistema coletivo em que operam sinergicamente personalidades imaginativas concretas, cada uma contribuindo com o melhor de si, num clima entusiástico, graças a um líder carismático e a missão compartilhada" (p.594).

Manzini considera que as comunidades criativas

\begin{abstract}
“nascem a partir de problemas colocados pela vida cotidiana contemporânea [...] aplicam sua criatividade para quebrar os modelos dominantes do pensar e fazer [...] resultam de uma original combinação de demandas e oportunidades" (MANZINI, 2008, p.65).

"grupos de pessoas engajadas para a solução ou criação de novas possibilidades para problemas comuns, a partir de um processo de construção de um conhecimento social voltado para a promoção da sustentabilidade social e ambiental". (Manzini, 2006, p.2)
\end{abstract}

Já para Fialho (2011) o conceito de comunidade criativa foi construído em torno da atividade de um grupo e indivíduos com interesses comuns que, em um dado domínio, compartilham práticas mutuamente negociadas, compreensões, crenças, opiniões, valores e comportamentos.

Da mesma forma existem as "comunidades de prática", termo cunhado por Etienne Wenger que considera que são um grupo de pessoas que se importa com questões, em comum das quais compartilham e desenvolvem conhecimento e prática nesse domínio.

Macedo relata que as comunidades de prática são compostas por pessoas que desenvolvem e discutem a respeito de uma atividade comum, podendo ser a principal ocupação das pessoas da comunidade, algo que se faz no decorrer de sua principal ocupação ou que se faz nas horas livres (MACEDO, 2010, p. 143).

Já Peter Senge (1999, p.21) as comunidades de prática são

\begin{abstract}
"As pessoas expandem continuamente sua capacidade de criar resultados que elas realmente desejam, onde maneiras novas e expansivas de pensar são encorajadas, onde a aspiração coletiva é livre, e onde as pessoas estão constantemente aprendendo a aprender coletivamente".
\end{abstract}

Portanto, para a constituição de uma comunidade de prática é necessário que existam três elementos crucias: o domínio, a comunidade e a prática.

A criatividade coletiva está baseada em grupos interdisciplinares de diferentes níveis de saberes, por vezes autônomo, mas colaborativos em prol de um objetivo comum, objetivando o mercado inovador.

E Harman e Hormann, (1990, p.95) descreve sobre a origem da palavra comunidades e sobre a vivência em comunidade.

"[...] A palavra communitas do latim da à ideia de companheirismo ou a sensação de estar em comunidade. Um grupo em comunidade compreende indivíduos que partilham interesses ou vínculos comuns, muitas vezes vivendo no mesmo lugar, repartindo propriedades ou similaridades comuns".

Ainda diz que,

"outro valor importante para a formação de comunidades e a integração do trabalho e da vida no meio ambiente. A sociedade comunitária ideal possui como característica típica desenvolver ao trabalho sua integração nas comunidades autogeridas. [...] a comunidade em escala humana é um lugar onde a democracia participativa é possível, onde a ação consegue ver a necessidade de uma ativa 
interação na municipalização, onde a ação de cada indivíduo é repleta de significado e impacto".

Os grupos produtivos solidários se relacionam com todos os conceitos acima citados, pois são grupos com interesses em comum e em busca de um domínio por meio de prática, com o objetivo se capacitar para autogestão, serem capazes de integração e colaboração com outras comunidades, resolvendo de maneira criativa os seus problemas.

Por meio dos diversos autores clarifica-se sobre conceitos e relação entre as comunidades criativas, comunidades de prática e os grupos produtivos solidários da Economia Solidária.

\section{Economia Solidária}

A Economia Solidária é "uma forma diferente de trabalhar, produzir, comercializar e consumir. É o conjunto de atividades econômicas de produção, distribuição, consumo, poupança e crédito organizadas e realizadas solidariamente de forma coletiva e autogestionária.

Além da cooperação, a Economia Solidária trabalha por intermédio de Oficinas Solidárias, Assessoria, capacitação técnica e de autogestão e de investimento solidário." (Programa de Economia Solidária, 2012 a) $)^{1}$.

Segundo a Secretaria Nacional de Economia Solidária (SENAES), a Economia Solidária é:

“O conjunto de atividades econômicas - de produção, distribuição, consumo e poupança e crédito - organizadas e realizadas solidariamente por trabalhadores e trabalhadoras sob forma coletiva e autogestionária. Nesse conjunto de atividades e foras de organização destacam-se quatro importantes caracteristicas: cooperação, autogestão, viabilidade economica e solidariedade. É necessário perceber que esas caracteristicas, embora sejam complementares e nunca funcionem isoladamente, podem ser observadas e compreendidas objetivamente como categorias analiticas diferentes, mas sempre presentes na Economia Solidária." (SENAES 2005, p.11).

O Ministério do Trabalho e Emprego (MTE) define a Economia Solidária como:

"[...] um jeito diferente de produzir, vender, comprar e trocar o que é preciso para viver. Sem explorar os outros, sem querer levar vantagem, sem destruir o ambiente. Cooperando, fortalecendo o grupo, cada um pensando no bem de todos e no próprio bem.

A economia solidária vem se apresentando, nos últimos anos, como inovadora alternativa de geração de trabalho e renda e uma resposta a favor da inclusão social. Compreende uma diversidade de práticas econômicas e sociais organizadas sob a forma de cooperativas, associações, clubes de troca, empresas autogestionárias, redes de cooperação, entre outras, que realizam atividades de produção de bens, prestação de serviços, finanças solidárias, trocas, comércio justo e consumo solidário". (Ministério do Trabalho e Emprego - MTE, 2011).

A Economia Solidária segue alguns princípios, que são: a cooperação, a autogestão, a solidariedade e a atividade econômica.

A "cooperação acontece quando um grupo contribui com suas energias para a realização de tarefas de interesse comum", trabalhando coletivamente e partilhando dos resultados desse trabalho com responsabilidade solidária.

A autogestão também é um trabalho coletivo. Todos participam de todo o processo de Gestão e Produção de trabalho e renda, desde o planejamento estratégico, da produção, da comercialização, do compartilhamento de tarefas, das idéias, das decisões e sempre dividindo a renda de forma igual.

O princípio da solidariedade permeia em todas as ações na Economia Solidária por meio da inclusão de todas as pessoas nos benefícios do desenvolvimento dos empreendimentos econômicos solidários. 
E a atividade econômica está diretamente ligada à produção, a comercialização, e ao consumo, pois todas essas etapas se referem à geração de trabalho e renda, segundo o Programa de Economia Solidária $(2012, \mathrm{~b})^{2}$.

\section{Meios de pesquisa e desenvolvimento dos Grupos Produtivos Solidários}

Os integrantes dos grupos produtivos do programa de Economia Solidária possuem várias formas de pesquisar e por diversos meios, sendo estes: visitas em lojas especializadas, internet, revistas do segmento mercadológico, vitrines, cursos de capacitação entre outros, para a exploração do potencial criativo.

As habilidades pré-existentes são aperfeiçoadas com o tempo de prática, pela troca e compartilhamento de informação e observação entre os participantes do grupo produtivo.

Cada grupo possui uma limitação para a criação de seus produtos, para não gerar concorrência dentro do programa entre os grupos de produção. Esta limitação se da por meio da técnica de especialidade do grupo e/ou por uma linha de produtos trabalhada dentro do segmento mercadológico proposto.

Os grupos produtivos é quem faz as criações de novos produtos, utilizando das habilidades e técnica de especialidade, faz-se um produto que posteriormente será aprovado por superiores do programa, os quais orientam os grupos semanalmente em processos de autogestão, tais como: custo e escolha de matéria-prima, contabilidade, vendas entre outros.

Os participantes dos grupos produtivos devem sempre estar atualizados dos materiais que possam inserir em sua produção e contribuir na qualidade e diferencial dos produtos solidários.

A prática e o uso da criatividade é fator crucial para a inovação, diferencial dos produtos em relação aos industrializados, enquanto o trabalho artesanal garante exclusividade e personalização, aspectos que agregam valor ao produto final.

Os grupos produtivos da Economia Solidaria são selecionados e divididos de maneira em que os interessados percebam suas aptidões e habilidades dentro dos atuais segmentos do programa, conforme figura abaixo.

Figura 04 - Segmentos atuais do programa de economia solidária.



Fonte: própria, 2011.

Atualmente o programa está dividido em segmentos mercadológicos de artesanato, alimentação, vestuário e prestação de serviços.

O processo para a inclusão a Economia Solidaria inicia-se pela procura espontânea de pessoas e pelos Centros de Atendimento (CRAS) espalhados pelas regiões da cidade. Com a formação de um grupo de interessados é iniciado um ciclo de palestras e dinâmicas, denominado de "sensibilizações" divididas em três etapas, sendo a primeira: a conscientização da exclusão do mercado capitalista 
Preto, Seila Cibele Sitta; Fialho, Francisco Antônio Pereira; Figueiredo, Luiz Fernando Gonçalves de

de trabalho. Na segunda palestra, inicia a introdução sobre o que é a economia solidária, enquanto ação e inclusão social e oportunidade de geração de trabalho e renda para aqueles que estão em vulnerabilidade social. E a terceira e última palestra falam sobre os princípios que regem a Economia Solidária e investigam sobre as aptidões e habilidades dos interessados. Neste ciclo de palestras acontecem as socializações entre os participantes devido a trocas de informações, as quais são mediadas por técnicas orientadoras do programa.

Pode-se dizer que a criatividade já esta presente, desde o inicio do processo, que é a seleção dos candidatos, pois, além atuar como catalizadores na inclusão social, disseminam o programa de Economia Solidária. E os participantes que ficam todo o ciclo de palestras, entram mais motivados a enfrentar a nova proposta de trabalho em sistema de cooperação, solidariedade e autogestão, princípios estes, regidos pela Economia Solidária.

Após o ciclo de palestras, os interessados estão se conhecendo e se agrupando por aptidões e habilidades, para formação futura do grupo produtivo e um novo empreendimento solidário. Sendo assim, as capacitações de cada grupo são iniciadas para seu desenvolvimento e planejamento do empreendimento econômico solidário atuar neste novo cenário e mercado de trabalho.

Logo abaixo são apresentados alguns produtos de alguns grupos produtivos.

$\mathrm{Na}$ figura 05 , apresenta-se um dos produtos desenvolvidos pelo grupo produtivo no segmento de vestuário, que produz roupas de dormir.

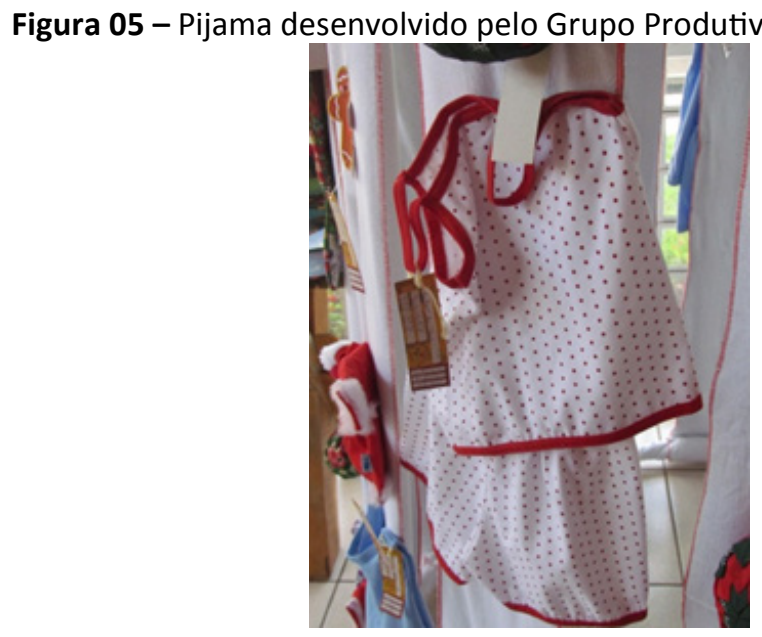

Fonte: própria, 2011.

O grupo produtivo é constituído por duas mulheres, já senhoras que produzem roupas de dormir, tais como, pijamas, baby-dolls, camisolas entre outros. As duas integrantes fizeram capacitações, uma de corte e costura e outra de modelagem, possibilitando a criação e desenvolvimento de novos produtos. Atualmente o grupo trabalha em local cedido pelo programa de economia solidária.

Este grupo possui um público com perfil diversificado (sexo, faixa etária e classe social), mas que procuram produtos de custo acessível e de qualidade. As produtoras utilizam a estamparia dos tecidos como identidade de seu grupo. O produto se difere em modelos, estampas e combinações de cores. Primam pela qualidade e buscam na própria matéria-prima custo, qualidade e beleza, para atenderem seu público e demanda.

As produtoras fazem pesquisas em lojas especializadas e lojas que vendem roupas de dormir, acompanhando sempre as tendências e técnicas para atualização de seu produto e criações de novos modelos.

A criatividade esta presente desde o início do processo, pois, é na matéria prima que as produtoras encontraram a condição de atender seu público diversificado, proporcionando no produto final conforto, beleza e custo acessível.

O grupo produtivo tem seu retorno por meio da sustentabilidade do grupo e da aquisição de novos equipamentos adquiridos por condições próprias. O grupo respeita os princípios da Economia 
Solidária e praticam o preço justo, sem perderem qualidade e beleza, que no mundo do vestuário e aspecto fundamental. Atendem sob encomenda, produzem produtos personalizados, o qual proporciona ao grupo um diferencial tanto no produto quanto no atendimento.

$\mathrm{Na}$ figura 04 , apresenta-se produtos desenvolvidos pelo grupo produtivo no segmento de artesanato.

Figura 06 - Produtos desenvolvido pelo Grupo Produtivo no segmento de Artesanato.

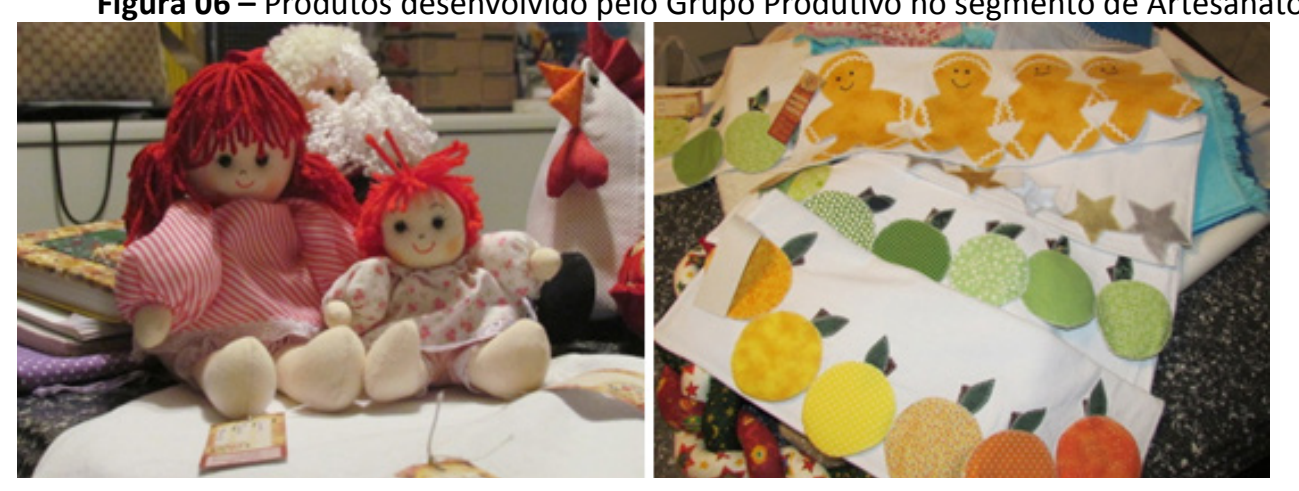

Fonte: própria, 2011.

O grupo produtivo no segmento de artesanato é composto por duas mulheres, sendo estas, mãe e filha, que trabalham com artesanato e com a técnica de patch apliqué. Os produtos são delimitados em bonecas e moda para a casa.

Para a criação das bonecas leva-se tempo e o trabalho deve ser muito organizado devido à complexidade para tal produto. Muitos detalhes devem ser pensados, para que a boneca tenha um resultado satisfatório.

Alguns modelos de bonecas possuem essências, as quais além de decorar, ainda perfuma o ambiente. Este diferencial agrega ainda mais valor ao produto artesanal. $\mathrm{O}$ grupo produtivo trabalha também com encomendadas, criando novas bonecas de acordo com a necessidade e estilo do cliente e possui as bonecas a pronta entrega.

A linha moda da casa possui vários produtos, porém merece destaque os panos de prato que possuem o barrado todo em técnica de patch apliqué. Para tal técnica a criatividade entra em ação, pois o grupo trabalha com temáticas, onde são criadas as peças que farão parte de desse tema. Criase inicialmente o desenho, posteriormente trabalha toda a modelagem de cada "objeto" na formação da composição temática, para posteriormente serem cortados os tecidos, os quais tem relação entre cores, estampas e seus temas para serem aplicados e acabados no produto final.

$O$ grupo produtivo faz pesquisas constantes em meios como revistas especializadas, internet $\mathrm{e}$ cursos, na busca de aprimoramento e inovações artesanais.

$\mathrm{Na}$ figura 07 , apresenta-se produtos desenvolvidos pelo grupo produtivo no segmento de alimentação.

Figura 07 - Produtos desenvolvidos pelo Grupo Produtivo no segmento de alimentos.

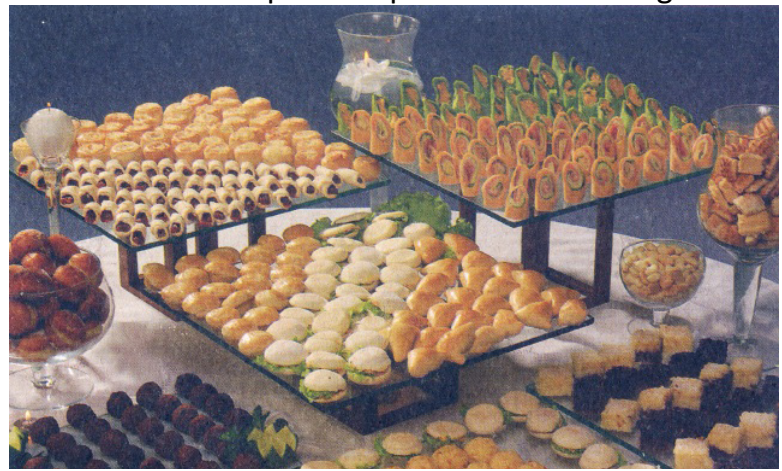

Fonte: Material Promocional Economia Solidária, 2011 
Preto, Seila Cibele Sitta; Fialho, Francisco Antônio Pereira; Figueiredo, Luiz Fernando Gonçalves de

O grupo produtivo no segmento de alimentos é constituído por cinco mulheres que trabalham com salgados e doces e atualmente estão focando para servir em eventos ou empresas como coffee break.

Há cinco anos trabalham na busca de novos produtos e sempre aprimorando o que já tem em cardápio para apresentação aos consumidores.

A aparência estética e formal dos salgados e doces tem grande importância na apresentação, tanto para o sentido sensório visual, quanto gustativo. Portanto, além de se preocuparem com as fórmulas e os segredos das receitas, também devem se preocupar e serem criativas com a apresentação dos produtos sobre a mesa posta, fazendo com que os consumidores sintam vontade de comer e saboreá-los. Por meio de cortes, cores, arranjos e aparatos a mesa fica bem elaborada e organizada, valorizando os produtos e estimulando seu consumo.

\section{Metodologia}

Este artigo apresenta um estudo por meio de pesquisa bibliográfica, a qual se detém de material já publicado. Lakatos (2010, p. 166) define a pesquisa bibliográfica como:

"pesquisa bibliográfica ou de fontes secundárias, abrange toda a bibliografia já tornada pública em relação ao tema de estudo, desde publicações avulsas, boletins, jornais, revistas, livros, pesquisas, monografias, teses, material cartográfico etc., até meios de comunicação oral: rádio, gravações em fita magnética e audiovisuais: filmes e televisão."

Esta pesquisa possui caráter exploratório, ao proporcionar uma visão geral, na obtenção de conhecimento sobre o assunto a partir do levantamento bibliográfico, em etapa inicial e entrevistas qualitativas junto de levantamento fotográfico para diagnosticar o uso da criatividade dos grupos de produtivos da Economia Solidária.

\section{Considerações Finais}

De acordo com a fundamentação teórica levantada nos pontos de criatividade e potencial criativo, conclui-se que a criatividade surge da necessidade do homem.

Os grupos produtivos são comparados às comunidades criativas, e comunidades de prática por praticarem reuniões e compartilhamento de informações e conhecimento em busca de um único interesse, sendo este a inclusão ao mercado de trabalho e geração de trabalho e renda.

A troca dessas informações e experiências proporciona aprendizado ao individuo que também compartilha dentro de seu grupo, nivelando-o e estimulando o trabalho de forma cooperada.

Os grupos estão sempre buscando capacitações, que além de melhorar o seu produto, proporciona maior visão e conhecimento de seu empreendimento, explorando também seu potencial criativo.

Os grupos produtivos da Economia Solidária atuam em segmentos mercadológicos distintos, o qual é orientado para um foco, facilitando a pesquisa para criação e desenvolvimento de novas propostas de produtos e serviços.

O grupo deve conhecer o processo produtivo em sua totalidade, para que possa combiná-lo com os princípios da Economia Solidária e comercializá-lo com o preço justo.

Portanto a criatividade é exercitada diariamente dentro dos grupos e cada vez mais o potencial criativo se torna maior e mais flexível, resultando em melhorias e inovações para os produtos e serviços, os quais proporcionam maior visibilidade ao empreendimento, conhecimento e valorização do trabalho artesanal, além do retorno financeiro para o grupo que teve como objetivo a inclusão social e a geração de trabalho e renda e sustentabilidade.

A criatividade por ser inata ao homem pode ser trabalhada e obter resultados positivos, mesmo sem grandes recursos, seja estes cursos para utilização de técnicas sobre criatividade, ou investimentos 
A importância da criatividade no trabalho artesanal dos grupos produtivos de um ... de Economia Solidária

em materiais que ensinam sobre. Basta ter uma necessidade, no caso dos grupos produtivos, a geração de trabalho e renda, que por meio de compartilhamento de informações e experiências os grupos acharam soluções criativas para suas demandas e sustentabilidade, agregando valor ao trabalho artesanal solidário.

\section{Notas}

${ }^{1}$ Fonte:<http://economiasolidaria.londrina.pr.gov.br/quemsomos.aspx>.Acesso em 24/10/11.

${ }^{2}$ Fonte:<http://economiasolidaria.londrina.pr.gov.br/principios.aspx>. Acesso em 24/10/11.

\section{Referências}

ALENCAR, E.S. A gerência da Criatividade. São Paulo: Makron Books, 1996.

AYAN, J. AHA! 10 maneiras de libertar seu espírito criativo e encontrar grandes ideias. gerência da Criatividade. São Paulo: Negócio Editora, 1998.

DE MASI,D. Criatividade e grupos criativos. Rio de Janeiro: Sextante, 2003.

DICIONÁRIO AURÉLIO. Disponível em: <http://www.dicionariodoaurelio.com/Criatividade>. Acesso em 24/02/12.

FIALHO, F. A. P. Psicologia das Atividades Mentais: introdução às ciências da cognição. Florianópolis: Ed. Insular, 2011.

HARMAN, W; HORMANN, J. O trabalho Criativo. São Paulo: Cultrix, 1990.

LAKATOS, E. M.; MARCONI, M. A. Fundamentos de Metodologia Científica. 7.ed. - São Paulo: Atlas, 2010. 320p.

MACEDO, M.et.al. Gestão do conhecimento organizacional. Florianópolis: Ed. UFSC, 2010.

MANZINI, Ezio. Design para a inovação social e sustentabilidade: comunidades criativas, organizações colaborativas e novas redes projetuais. Ezio Manzini; [coordenação de tradução Carla Cipolla; equipe Eliza Spampinato, Aline Lys Silva]. Rio de Janeiro: E-papers, 2008.

Ministério do Trablho e Emprego. Disponível em: <http://www.mte.gov.br/economiasolidaria.oque. asp>. Acesso em 24/10/11.

OSTROWER, F. Criatividade e processos de criação. Petrópolis: Vozes, 2007.

PREDEBOM, J. Criatividade: abrindo o lado inovador da mente: um caminho para o exercício prático dessa potencialidade, esquecida ou reprimida quando deixamos de ser crianças. São Paulo: Atlas, 2002.

PROGRAMA MUNICIPAL DE ECONOMIA SOLIDÁRIA. Disponível em: <http://economiasolidaria. londrina.pr.gov.br/quemsomos.aspx>. Acesso em 24/10/11.

em $24 / 10 / 11$

Disponível em:<http://economiasolidaria.londrina.pr.gov.br/principios.aspx> . Acesso

SENGE, P. 1995. A Quinta Disciplina: caderno de campo - estratégias e ferramentas para construir uma organização que aprende. Rio de Janeiro, Qualitymark Ed., 544p.

VIGOTSKY, L.S. Psicologia pedagógica. São Paulo: Martins Fontes, 2001. 
Preto, Seila Cibele Sitta; Fialho, Francisco Antônio Pereira; Figueiredo, Luiz Fernando Gonçalves de ZANLUCHI, F.B. O brincar e o criar: as relações entre atividade lúdica, desenvolvimento da criatividade e educação. Londrina: O Autor, 2005.

ETIENNE WENGER. Disponível em:< http://wenger-trayner.com/wp-content/uploads/2012/01/06Brief-introduction-to-communities-of-practice.pdf>. Acesso em 20/02/2012. 